\title{
Teacher Aides: The Fine Art of Balance
}

\author{
Miriam Ferguson
}

\section{Position Paper}

Keywords: inclusion, teacher aide

\begin{abstract}
Teacher aides have been part of New Zealand classrooms for many decades. Initially, they were employed to perform clerical and supervisory duties that required no professional training, such as typing, duplicating and playground supervision. Over the years, however, their role has changed significantly. They now play a pivotal role as a 'people resource' in supporting the New Zealand Ministry of Education's philosophy of inclusion.
\end{abstract}

The most effective teacher aides are working in positive inclusive contexts in which they are respected and valued, however, their role is full of inconsistencies and will likely to remain so until there are some systemic changes made in government policy. This paper argues that teacher aides can be a powerful resource; however their use must be carefully considered so that the fine art of balancing the social and academic needs of a student with special educational needs is sensitively planned, and where possible, underpinned by the professed needs of that student and their family. Teacher capability needs to be built so there is increased ownership for all students.

"... nowhere is education an uncomplicated 'good'; it produces both justice and injustice, equity and inequity and the issue is to understand why, when and how" (Walker, 2003, cited in Rutherford, 2009, p.90).

\section{History/Background}

Traditionally, students who were deemed to have significant special educational needs (SEN) were schooled separately in special units attached to schools, or in special schools, which were staffed with specialist teachers. Special Education practices

\footnotetext{
1 All New Zealand schools have a Board of Trustees elected by the parent community responsible for the governance of the school.
}

played an important role in legitimising the identification, separation and schooling of students with SEN, which, within the context of that time, was an honest attempt to provide safe and suitable schooling. Prior to this, children with SEN were not entitled to go to school.

In the late 1980s, the New Zealand education system underwent a series of political reforms which saw the devolution of government control to local selfmanaging schools. The 1989 Education Act granted students with disabilities the right to attend local state schools if parents so chose. Boards of Trustees ${ }^{1}$ were given the responsibility to identify students who had SEN and to develop and implement teaching and learning approaches that addressed the needs of these students. The provision of teacher aide support became, and has continued to be the most common way in which schools responded to these students' needs (Rutherford, 2009). Teacher aides were seen as the solution to inclusion (Ward, 2011).

In 1996, the policy Special Education 2000 was introduced. This policy framed the provision of education for students with SEN, promising a world-class inclusive education system (Ministry of Education, 1996). This is defined as "the provision of extra assistance, adapted programmes or learning environments, specialised equipment, or materials to support children and young people with accessing the curriculum in a range of settings" (Ministry of Education 2010, npg). However, while the policy aimed to create a world-class inclusive education system, its very definition demonstrates a greater focus on resourcing than aspects of human rights so critical to inclusive education (Rutherford, 2011). Despite this apparent contradiction, support for inclusion can also be found in other New Zealand policies such as the New Zealand Disability Strategy, which aims for an inclusive society, and the initiative Success for All - Every School, Every Child (Ministry of Education, 2010) which identifies a four-year plan of action to achieve a fully-inclusive education system. 
These policies and initiatives reflect New Zealand's move towards more inclusive schools and inclusive societies, a movement which is becoming an international phenomenon (Brown, 1997). The major impetus for inclusive education has been issues of human rights and the proposition that inclusive education is more effective (Lindsay, 2007). Rutherford (2011) points out that the move to inclusion can also be seen as egalitarian, with the promise of redistributed resources according to need. However, Rutherford also notes that equality stated in written laws is often unrealised in practice. "Rights on paper, such as those of New Zealand's 1989 Education Act, are simply words. And they remain so in the absence of relationships with people to understand and care enough about a person or situation to recognise and enact rights in the face of injustice - to move from the noun, a right, to the verb, do right by"(p.113).

The move to inclusion was not synonymous with appropriate resourcing however. In particular, the lack of qualified professionals with whom to support the inclusion of students with SEN have meant that teacher aides are often utilised, within a cultural context that largely devalued people with disabilities (Giangreco, Edelman, Broer and Doyle, 2001). Over the years, the ready availability and the cost-effectiveness of teacher aides resulted in this resource being maintained and expanded in the absence of a supportive theoretical base or efficacy data (Giangreco, Edelman, Broer and Doyle, 2001). As Giangreco et al., (2001) argue "There is no compelling data suggesting that teacher aides are an effective way to educate students with disabilities in inclusive classrooms" (p.59). In other words, the evidence-base for this resource is not established. Why then, do we still have teacher aides? Giangreco et al., (2001), suggest that history, economic factors, changing demographics, parent advocacy, administrative convenience, ease, expediency and momentum are all contributing factors to the continuation of the use of teacher aides to facilitate inclusion of students with SEN.

Although there is a limited research-base related to the role and efficacy of teacher aides, there is sound theory underpinning the practice of using teacher aides in providing support for students with SEN in the mainstream. Psychologist Vygotsky proposed that children learn through interactions with their surrounding culture. This theory, known as the socio-cultural perspective, states that the cognitive development of children and adolescents is enhanced when they work in their Zone of Proximal Development (ZPD). To reach the ZPD, children need the help of adults or more-competent individuals to support or scaffold them as they are learning new things. according to Vygotsky's theory, children can do more with the help and guidance of an adult or other more-experienced person than they can do by themselves. The Zone of Proximal Development defines skills and abilities that are in the process of developing. The ZPD is the range of tasks that one cannot yet perform independently, but can accomplish with the help of a more-competent individual such as a teacher aide. Since children are always learning new things, the ZPD changes as new skills are acquired. Scaffolding is the structure or guidance of a more-experienced person. There are many different ways of scaffolding, including breaking the task down into smaller steps, providing motivation, and providing feedback about progress - tasks very often provided by a teacher aide. Scaffolding is seen to instill the skills necessary for independent problem solving in the future.

\section{The Role of the Teacher Aide}

Since the 1989 Education Act and the movement towards inclusion, the role of the teacher aide has shifted from largely clerical work and resource preparation to actively supporting the mainstreaming of children with SEN (Clegg, 1987). At the time when inclusive education was emerging as a preferred model of education, there was advice that serious consideration be given to the allocation of teacher aides for it was considered that without them, inclusive education could not succeed (Clegg, 1987). This belief lingers. In a US study, Giangreco and Suter (2010) found that 80 percent of schools they surveyed reported that teacher aides were viewed as the way rather than a way to support students with SEN, that teachers were minimally or superficially involved with students, and that students with SEN were dependent on teacher aides. They also reported that current literature shows that teacher aides' responsibilities have become increasingly instructional, operating with high levels of autonomy, making instructional decisions, providing the bulk of instruction to students and doing so without adequate professional direction (Giangreco \& Suter, 2010).

So what are the qualifications, conditions and pay of the personnel we assign to students who present the most challenging learning and behavioural challenges?

In New Zealand there is no national policy regarding schools appropriate use of teacher aides (Rutherford, 2009). However, there are guidelines published by the Ministry of Education (2012) for parents and caregivers. These guidelines advise that it is the teacher who remains responsible for the child's 
learning and behaviour. The child's teacher will work with the child, and the child should not be supported only by the teacher aide. There is an expectation that the class teacher will meet with the child's teacher aide weekly, and give the teacher aide feedback. Also, the Ministry of Education advise that the aim should be to build the child's independence by using natural supports such as including the child in a group and facilitating work with other students so that the child does not feel singled out for attention (Ministry of Education, 2012).

Although there is no national database of teacher aide employment details, a search on the New Zealand Ministry of Education website indicates that teacher aides are paid according to their skill levels, qualifications and responsibility. A teacher aide beginning at Grade $A$ (where there is a need for close supervision and no need to exercise judgement) starts on $\$ 15.26 \mathrm{c}$ per hour rising to the maximum of \$15.58 per hour (NZEI Collective Agreement for Special Education Assistants). A Grade B rate (advanced knowledge, skills and experience) ranges from \$15.58c per hour to \$19.29c per hour. To attain Grade C ( $\$ 19.29$ c to $\$ 23.95$ c per hour) a teacher aide must have management, administrative and/or financial responsibilities.

\section{What are the Issues?}

The permanency of teacher aide positions is often tenuous. In her 2009 New Zealand study, Rutherford reported that none of the teacher aides in her research had permanent jobs because their employment depended on the availability of funding. Although teachers are paid centrally through government, unless you are a teacher aide for one of the very small number of students with Ongoing Resourcing Scheme (ORS) funding, you are likely paid from the school Special Education Grant (SEG), a grant provided to every school in New Zealand to support students with SEN. From this grant, many necessities are vying for priority, including teaching resources for children with SEN such as books, videos, computer software, packaged teaching programmes and so on. As well as teacher aides, the school may also need to employ specialist teachers, psychologists, behaviour consultants, or provide professional development for teachers. The fact that teacher aides are employed periodically, year by year dependent on funding, and are paid hourly for the actual hours they work (they are not paid for breaks, school holidays and not of right for meetings - including the Individual Education Plan (IEP) meetings that the Ministry of Education expect, or resource preparation out-of-

2 The NZEI is the primary teacher union school hours) means that this is seldom a living wage. A living wage assumes 40 hours of work (King \& Waldegrave, 2014) however, most TAs work much less than this (Careers NZ website).

Research conducted by the New Zealand Educational Institute ${ }^{2}$ (NZEI) entitled Valuing the Work of Support Staff in Schools (2010) confirmed that, despite the skills required for the job, teacher aides in New Zealand are poorly remunerated, with little job security and uncertain hours. Why has there not been a challenge to these unsatisfactory conditions? Is it because teacher aides are to some extent a marginalised workforce, who do not strongly challenge the status quo? It is widely understood that funding from a school's SEG grant means a teacher aide may not be a priority. The Ministry of Education (1998) handbook Managing the Special Education Grant, advises that the SEG grant "allows schools to break away from the teacher aide mindset" (p.3). Recruitment does not seem to be an issue either as schools do not appear to have any trouble finding teacher aides: many, from my experience, are intelligent and caring women with school-aged children who take the position as it can fit around the needs of their family. The New Zealand Education Institute has recognised the worth of teacher aides and have strongly advocated for them, without much success (NZEI, 2010). It may be, therefore, that the current state of pay and conditions of teacher aides is simply a reflection of the governments determination to keep the cost of special education down.

\section{Training and Qualifications}

Also of concern is the fact that there is no prerequisite for training or qualifications to become a teacher aide. All that is necessary is a police check, to ensure they have not been convicted of serious criminal offences (Rutherford, 2011). As Giangreco et al., (2001) ponder, is it acceptable that the leastqualified are responsible for students with the most complex challenges to learning? Is it fair to expect those being paid what would arguably be described as a 'basic wage' to adapt and instruct? It is unsurprising that there were some ongoing questions in the Evaluation of the Introductory Professional Development Programme for Teacher Aides (Ministry of Education, 2004), about the sustainability of expertise in special education professional development if the teacher aide workforce is dependent on periodic contracts. None of this is new. Concerns about the qualifications and pay of teacher aides have been long standing. In 1987, Clegg concluded her thesis by recommending that the Department of Education (now the Ministry of Education) accept responsibility for the pre- and 
in-service training of ancillary staff, that in-service courses be developed and qualifications be gained, and that teacher aides be paid over the Christmas holiday break. Twenty-seven years later, change is slow in coming.

Similarly, in the 2002 review of Special Education 2000, Wylie recommended that there should be professional development in SEN for teachers as part of initial teacher education, and also for teacher aides (Ward 2011). However, while there are increasing opportunities for teacher professional development, professional development for teacher aides is largely dependent on whether individual schools deem it a priority and on the goodwill of the teacher aide to participate in professional development outside of their paid employment as they are not always paid to attend such opportunities. A further issue is that although professional development for teacher aides has been long identified as a need, findings from the Evaluation of the Introductory Professional Development Programme for Teacher Aides (Ministry of Education, 2004) showed that the knowledge teacher aides may gain from such opportunities is not necessarily utilised if the teachers they work with do not change their practice, and if the school systems do not change. Examples of this include a study by Kearney (2009) who found that nearly 13 percent of principals surveyed were unsure, or did not agree, that class teachers should be responsible for all students, and a report by the Ministry of Education (2004) that even after a introductory professional development programme for teacher aides was provided in 2002, only 10 - 17 percent of TAs indicated some progress in terms of teachers and TAs meeting regularly and working together.

\section{Roles and Responsibilities}

The lack of clarification of teacher/teacher-aide roles and responsibilities within schools is an issue welldocumented in research. Rutherford (2009) found that few teacher aides had job descriptions, and most spoke of carrying out responsibilities that required them to do work they had no training for. This is despite research which shows that "clearly defined roles and responsibilities are important factors in perceived ability to make a difference" (Stevenson, 2012, p.60). Devecchi and Rouse (2010) also found that effective collaboration between teacher aides and teachers was beneficial for both adults and the children they support. Collaboration enabled consideration of multiple viewpoints, the collective solving of problems, and finding ways to make a difference. Instead of this, as Giangreco and Suter (2010) reported, most plans for the teacher aide role are transmitted orally with time being a limiting feature. With ill-defined roles and responsibilities it is unsurprising that teacher aides may work in a variety of ways, exceeding their prime role of the connector or the scaffolder Vygotsky proposed.

Rutherford (2009) observed inconsistencies in the way teacher aides are used in schools. The most effective were working in positive inclusive contexts in which they were respected and valued. These teacher aides used a range of strategies to simplify and interpret instructions, academic tasks and resource materials, scaffolded by a qualified teacher. In my experience as an RTLB, this optimal situation is rare. Rutherford recognised there were also teacher aides who adapted on the run, working as untrained teachers using judgements and resourcefulness to support student's learning, which she saw was a pressure valve for teachers - more common in my experience. But she also recognised that many teacher aides assumed full responsibility for their student with minimal input from teachers - the aide, she noted, was in effect, the teacher, or in many cases, a babysitter. It appears as Stevenson (2012) found, that a lack of teacher experience and knowledge about SEN leads to a lack of supervision. Teacher aides then make curricular decisions on their own.

Ward (2011) reports that many teachers are relieved that students with SEN come with an attached teacher aide. Whether willingly or reluctantly, many classroom teachers relinquish primary responsibility for the education of students with disabilities to teacher aides. Kearney (2009) found that because of teacher's lack of knowledge and understanding, the handing over of disabled students to teacher aides was accepted practice. This, she found, was particularly true in secondary schools, where teacher aides generally spent more time working with students one-on-one. It is evident that the Ministry of Education guidelines do not match the reality of practice in the NZ classroom. As Giangreco et al., (2001) point out, while "much of the literature trumpets the politically correct rhetoric that teacher aides work under the direction and supervision of qualified professionals, that research is showing descriptions of teacher aides left to fend for themselves without appropriate training, supports and supervision" (p.58).

\section{Enabler or Barrier to Inclusion?}

According to Stevens (2010), a major reason for placing students with disabilities in regular classes is to enable them to reap the social and academic benefits afforded their peers without disabilities. However, the presence of teacher aides can work against the very inclusion they are employed to facilitate. Balancing the academic and social needs of 
a student is an ongoing challenge and teacher aides can inadvertently intensify the isolation of students with disabilities even though the regular classroom is considered to be an ideal setting in which to increase peer interactions and relationships. Stevenson (2012), found for example, that 90 percent of a student's interaction with peers occurred when the teacher aide was not in the vicinity of the student. Giangreco and Suter (2010) concur, saying that teacher aide proximity impedes the number of interactions between students and classmates, creating stigmatisation and dependence. Getting students with SEN accepted by other students and teachers is a particular challenge for both primary and secondary teacher aides. Secondary students in particular, on account of their developmental stage, are more likely to react negatively towards being singled out and secondary school teacher aides are more concerned about being disrespected by students (Stevenson 2012).

Literature shows that additional to the isolating influence of teacher aides on peer relationships, teacher aides may also interfere with teacher's engagement with students with SEN, encourage dependence on teacher aide support, limit students development of autonomy and control and affect their sense of identity (Causton-Theoharis, 2009; Giangreco \& Suter, 2010; Rutherford, 2011; Stevens, 2010). They can also promote insular relationships between the teacher aide and the student, a feeling of being stigmatized, loss of gender identity and provocation of behaviour problems. Additionally, proximity can also mean that there is less responsibility taken by classroom teachers, and limitations on receiving competent instruction (Causton-Theoharis, 2009; Giangreco \& Suter, 2010; Rutherford, 2011; Stevens, 2010). All students deserve to receive their primary instruction from highly qualified general and special educators. Yet, if you are a student with SEN, the likelihood is that you receive a substantial part of your education indirectly, from a teacher aide who is inadequately prepared, trained and supervised (Giangreco \& Suter, 2010). The question persists... do we undervalue them or have low expectations for them? And, as Giangreco et al., (2001) wonder; "Are the outcomes comparable to those who have consistent interactions with qualified professionals? Is there a lingering, unspoken perception that students with disabilities do not need or deserve the services of qualified professional educators?" (p.59).

\section{The use of Teacher Aides to Facilitate Inclusion}

Considered use of teacher aides, however, can indeed provide the connecting or linking role: interpreter, mediator and advocate to support academic and social inclusion. Rutherford (2011) asks us to consider the perspective that teacher aides, knowing and caring about students in terms of their humanity and competence, can also result in recognition and addressing of injustices experienced by students. Therefore, they "may act as agents of social justice in 'doing right by' the students they serve, partially alleviating the inequities generated by an increasingly meritocratic education system" (p. 96).

So, under what circumstances are teacher aides best used to facilitate inclusion? How can teacher aides work so that they are balancing the student's need for support with their development of autonomy and control, both socially and academically? There is a general consensus through the literature regarding this. A common observation throughout literature is that teacher aides should not have the primary instructional responsibility (Causton-Theoharis, Giangreco, Doyle \& Vadasy, 2007; Giangreco, Doyle, Halvorsen \& Broer, 2004; Giangreco, Edelman, Luiselli \& MacFarland, 1997; Stevens, 2010). There is a need to build teacher capacity so that there is increased teacher ownership for all children. Whanaungatanga, or building relationships, and manaakitanga, the ethic of caring are integral in culturally-inclusive classrooms. Therefore, the relationship a classroom teacher has with a child is paramount. (Macfarlane, Macfarlane, Savage \& Glynn, 2012). Building teacher capacity, particularly in differentiation, increases the amount and quality of instructional time for students with SEN. The classroom teacher's role needs to be explicitly clarified as the instructional leader, and learning activities need to be physically, programmatically and interactionally planned with all class members, including those with SEN. Differentiation of the curriculum should be a focus in pre-service training and in-service professional development, a skill, by my experience, particularly lacking in secondary settings.

Although the recommendation that the classroom teacher should have primary instructional responsibility for all children makes sense, it is much more difficult to achieve. Research has shown that there is a long-held belief by some teachers, school principals and parents that children with SEN need teacher aides (Kearney, 2009). Principals, teachers and parents need to be educated in inclusive principles. This is particularly difficult in the current educational climate in New Zealand with the focus on academic achievement, meeting National Standards in the primary sector, and National Certificate of Educational Achievement targets in the secondary sector. There is a very real tension between the Ministry of Education's stated principles of inclusion and their current direction of measuring and judging schools by their academic outcomes. Perhaps change, in the first instance, needs to come 
at this level.

Another key part of the solution is an upskilled teacher aide workforce. As Lindsay (2007) points out, the size of the teacher aide workforce now presents a major opportunity for development. If we are to persist in our use of teacher aides to support inclusion, it seems desirable that they should be explicitly and extensively trained in evidence-based learning approaches and in behaviour management (Causton-Theoharis et al., 2007; Giangreco et al., 1997). Despite the assertion by Giangreco et al., (2001) that there is no compelling data suggesting that teacher aides are an effective way to educate students with disabilities in inclusive classrooms, there is research data to show that teacher aides can make a difference if they are trained in evidencebased approaches. Lindsay (2007) found that a programme aimed to teach teacher aides how to facilitate interactions between students with SEN and their peers was successful in doubling facilitative behaviour, and that student interaction, which increased 25 fold, was maintained. Stevens (2010) found that training and feedback given to a teacher aide for a peer support programme indicated more frequent and longer social interactions between those with SEN and those without. Causton-Theoharis et al., (2007) found that teacher aides trained in a researchbased reading approach accelerated the progress of children including those with SEN.

However, building and retaining this 'specialist' teacher aide arm of the teaching workforce would require the Ministry of Education to revisit the pay and conditions of teacher aides. Teachers and teacher aides would also need to have clear roles and responsibilities, and opportunities to collaborate with monitoring and feedback. Training teacher aides would require a large financial commitment from the Ministry of Education, and ongoing collaboration between teacher aides and teachers requires a time commitment that may be unlikely to happen in the short term.

\section{Moving Forward}

What, then, can we do at the moment to ensure the best use of teacher aides? A start could be that the Special Educational Needs Co-ordinator (SENCO) of the school actively looks to provide professional development opportunities in evidence-based practice specific to the role of that particular teacher aide. Teacher aide involvement in TIPs for Autism (a Ministry-funded course supporting a collaborative team to provide an educational plan for individual students with autism) is one example of this. One other suggestion from the Evaluation of the
Introductory Professional Development Programme for Teacher Aides (Ministry of Education, 2004) is that teacher aides be involved in curriculum-related professional development within the school, which would incur a minimal cost and ensure the teacher aide had knowledge relevant to the specific school they were working in.

Teachers can also be encouraged to use peer support strategies. This promotes an understanding of similarities rather than difference. Segregation within the classroom and by withdrawal from class, of children who are Maori may be particularly culturally-inappropriate, and a barrier to the principle of Kotahitanga - unity and bonding. (Macfarlane, Macfarlane, Savage \& Glynn, 2012). Strategies such as cooperative group teaching, cooperative learning, peer tutoring and collaborative teaching are evidence-based, and need to be employed so that all students have the opportunity to be together in natural situations (Causton-Theoharis, 2009; Giangreco et al., 2004; Giangreco \& Suter, 2010; Stevens, 2010; Ward, 2011). Resource Teachers of Learning and Behaviour (RTLB) can facilitate and support this. It would follow then, that teacher aides would be hired for the classroom rather than an individual student (Giangreco, Edelman, Luiselli \& MacFarland, 1997; Ward, 2011).

The current evidence-base for the effective use of teacher aides in inclusive classrooms in New Zealand could also be added to by gathering information from the RTLB service. Teacher aides are often used for targeted interventions by RTLBs through their access to Learning Support Funding (LSF), and the effect of this is evaluated in post-data analysis. Collection of this postdata could provide further evidence of the efficacy of teacher aides within targeted programmes. Analysing this post-data may shed light on 'what works best' when using teacher aides in New Zealand classrooms.

Finally, an important component of teacher aide employment should be in involving students with SEN in making decisions about their own support. We need to recognise the importance of listening to students and to hear the stories of their experiences as we reflect on, review and question our attitudes. Students who are happy at school and who enjoy positive social relationships do better academically. We need to focus foremost on supporting student needs, then to clarify and align the roles of teacher/ teacher aide (Causton-Theoharis, 2009; Giangreco et al., 2004; Giangreco \& Suter, 2010; Stevens, 2010; Ward, 2011). Wherever practicable, we need always to be aiming at fading support to promote independence (Causton-Theoharis, 2009). This is the intention of scaffolding as Vygotsky envisaged, and is 
consistent with the Maori principle of Rangatiratanga, the need for self-determination (Macfarlane, Macfarlane, Savage \& Glynn, 2012).

The current use of teacher aides is inconsistent, and will likely to remain so until there are some systemic changes made in government policy. In particular, payment to teacher aides needs to be centrally funded so that their employment is not periodic and contestable. It would also help if they were specifically trained, that they were paid accordingly and that there were clear roles and responsibilities in their job description. These changes could facilitate a better evidence-based approach to these children's education.

Ultimately, how a teacher aide is used will be dependent on the individual situation, the child, significant others such as the child's family, teacher, and the wider unique context of their learning environment. Aspirationally, we want the best for our students, both socially and academically. Teacher aides can be a powerful resource, however their use must be carefully considered so that the fine art of balancing the social and academic needs of a student with SEN is sensitively planned, and where possible, underpinned by the professed need of that student.

\section{"Ko te ahurei o te tamaiti arahia o tatou mahi" Let the uniqueness of the child guide our work.}

\section{REFERENCES}

Brown, S. (1997). Special Education 2000: Developing a policy for inclusive education in New Zealand. New Zealand Annual Review of Education, 6, 141-156.

Careers NZ Website. Retrieved from www.careers. govt.nz/jobs/education/teacher-aide/about-the-job

Causton-Theoharis, J.N. (2009). The golden rule of providing support in inclusive classrooms: Support others as you would wish to be supported. Teaching Exceptional Children, 42(2), 36-43.

Causton-Theoharis, J.N., Giangreco, M.F., Doyle, M., \& Vadasy, P.F. (2007). Paraprofessionals. The "Sous-Chefs" of literacy instruction. Teaching Exceptional Children. 40(1), 56-62.

Clegg, J. (1987). Teacher aides in special education. A treatise submitted in partial fulfilment of the requirements for the Education of the Handicapped Course. Christchurch, New Zealand: Christchurch Teachers College.
Devecchi, C., \& Rouse, M. (2010). An exploration of the features of effective collaboration between teachers and teaching assistants in secondary schools. British Journal of Learning Support, 25, 91-99.

Education Aotearoa (Oct, 2011). Support staff face too many obstacles. Retrieved from www. educationaotearoa.org.nz/.../support-staff-face-toomany-obstacles...

Giangreco, M.F., \& Suter, J.C. (2010). Paraprofessionals in inclusive schools: A review of recent research. Journal of Educational and Psychological Consultation, 20, 41-57.

Giangreco, M.F., Doyle, M., Halvorsen, A.T., \& Broer, S.M. (2004). Alternatives to overreliance on paraprofessionals in inclusive schools. Journal of Special Education Leadership, 17(2), 82-90.

Giangreco, M.F., Edelman, S.S., Broer, S. M., \& Doyle, M. (2001). Paraprofessional support of students with disabilities: Literature from the past decade. Exceptional Children, 68(1), 45-63.

Giangreco, M.F., Edelman, S.W., Luiselli, T.E., \& MacFarland, S.Z.C. (1997). Helping or hovering? Effects of instructional assistant proximity on students with disabilities. Exceptional Children, 64(1), 7-18.

Kearney, A.C. (2009). Barriers to school inclusion: An investigation into the exclusion of disabled students from and within New Zealand schools. A thesis in partial fulfilment of the requirements for the degree of Doctor of Philosophy in Education. Palmerston North, New Zealand: Massey University.

King, P., \& Waldegrave, C. (2014). Living wage Aotearoa New Zealand 2014 update. Retrieved from http://www.livingwage.org.nz

Lindsay, G. (2007). Educational psychology and the effectiveness of inclusive education/ mainstreaming. British Journal of Educational Psychology, 77, 1-24.

Macfarlane, A.H., Macfarlane, S., Savage, C., \& Glynn, T. (2012). Inclusive education and Maori communities in Aotearoa New Zealand. In S. Carrington \& J. MacArthur, (Eds.). Teaching in inclusive school communities (pp.163-185). Qld, Australia: John Wiley \& Sons.

Ministry of Education (1995). Special education policy guidelines. Wellington, New Zealand: Ministry of Education.

Ministry of Education (1996). Special education 2000. Update to schools. Wellington, New Zealand: Author. 
Ministry of Education (1998). Managing the special education grant - a handbook for schools. Wellington, New Zealand.

Ministry of Education (2004). Evaluation of the introductory professional development programme for teacher aides/kaiawhina: Supporting teachers of students with special educational needs. Wellington, New Zealand: New Zealand Council for Educational Research.

Ministry of Education (2010). Success for all, every school, every child. Retrieved from: http://www. minedu.govt.nz/NZEducation/EducationPolicies/ SpecialEducation/OurWorkProgramme/ SuccessForAll.aspx.

Ministry of Education (2011). Learning more about support staff in schools: Results from surveys of principals and support staff members. Wellington, New Zealand: Ministry of Education.

Ministry of Education (2012). The role of the teacher aide. Information for parents and caregivers. Ministry of Education. Wellington, New Zealand.

Ministry of Education (2014). Support staff in schools collective agreement. Retrieved from: http://www. minedu.govt.nz/NZEducation/EducationPolicies/ SchoolEmployment/SupportStaff/SupportStaff/ CollectiveAgreement/PartThree.aspx

New Zealand Education Institute (2010). Valuing the work of support staff in New Zealand schools. Retrieved from www.nzei.org.nz/documents/.../ SS.../SS-Job-Evaluation-Final-Report.pdf

Rutherford, G. (2009). Curriculum matters for all students? Understanding curriculum from the perspectives of disabled students and teacher aides. Curriculum Matters, 5, 90-107.

Rutherford, G. (2011). "Doing right by" teacher aides, students with disabilities, and relational social justice. Harvard Educational Review, 81(1), 95-108.

Stevens, H. (2010). Impact of proximity of teachers' aides and support strategies. Kairaranga, 11(1), 40-44.

Stevenson, M.J. (2012). Making a difference: $A$ comparative study of the rules, responsibilities and perspectives of teacher aides in primary and secondary schools in New Zealand. Thesis submitted in partial fulfilment of the requirements for degree of Master of Educational Psychology. Palmerston North, New Zealand : Massey University.

Ward, A. (2011). Let's talk about teacher aides. Kairaranga, 12,(1) 43-50.

\section{AUTHOR PROFILE}

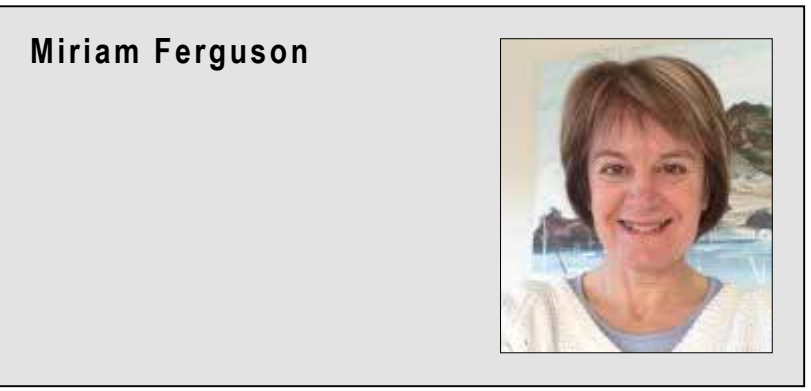

Miriam Ferguson is a training RTLB in Cluster 18, and this literature review was written as part of the Learning and Behaviour paper requirement. She was a teacher for many years in NZ Primary Schools before teaching in a SEN Department in a Secondary School in Bromley, London. This ignited an interest in Special Education. Returning to New Zealand she became a Supplementary Learning Support Teacher while completing a DipSpEd followed by a Masters of Education degree at Waikato University.

Miriams is interested in all things educational, in particular, the critical application of research to practice.

\section{Email:}

Miriamferg@hotmail.com 